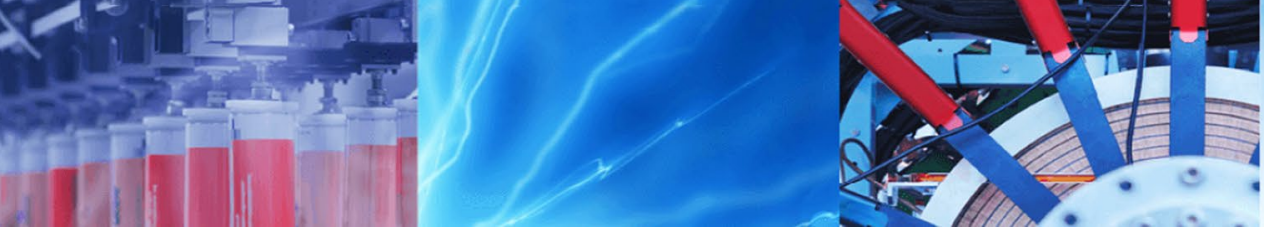

Research Article

\title{
Modelling the diffusion and exchange of ammoniacal nitrogen following deep placement of urea supergranules in wetland rice cultivation
}

\author{
Rémi Gaudin ${ }^{1,2}$ (iD
}

Received: 21 May 2020 / Accepted: 5 October 2020 / Published online: 14 October 2020

(c) Springer Nature Switzerland AG 2020

\begin{abstract}
Deep placement of urea in the form of supergranules is often recommended in transplanted rice cultivation as a means of avoiding nitrogen loss in the environment. As ammoniacal nitrogen produced by urea hydrolysis just after deep application is chemically stable in the anaerobic layer of the paddy soil, it is relevant to study the diffusion-exchange phenomenon affecting this ammoniacal-N. More precisely, numerical calculus was called on to solve the nonlinear diffusion-exchange equation, admitting spherical symmetry in this context. The adsorption isotherm for ammoniacal- $\mathrm{N}$ intervening in this equation was a Freundlich isotherm. Experiments performed in the laboratory (untransplanted situation) and in the field (transplanted situation) enabled the monitoring of the time course of ammoniacal-N concentration in the central position. The tortuosity factor was evaluated at 0.80 in the paddy soil. In the field, the diffusion-exchange phase was clearly separated from the ammonia assimilation phase. The limit between the two was evaluated in six replicates. The first-order mechanism of ammonia disappearance is interpreted as the indication of a tight physiological regulation at the carbon-nitrogen interface acting within roots pushed to their limit in growth and assimilative capacity. This limit is here reported at $12 \mathrm{mM}$ ammonia, attained $39 \mathrm{~d}$ after point application. This delay is enhanced when the tortuosity factor is reduced. Similar modelling in the context of cylindrical symmetry can be an option to study new urea fertilizers in the form of urea rods.
\end{abstract}

Keywords Oryza sativa $\cdot$ Urea supergranule $\cdot$ Ammoniacal nutrition $\cdot$ Tortuosity factor $\cdot$ Adsorption isotherm

\section{Introduction}

Nitrogen fertilizer is a key element for high yield in wetland rice cultivation. The classical method of urea broadcasting leads to important $\mathrm{N}$ losses by runoff and ammonia volatilization. To avoid detrimental effects on the environment, the technique of urea deep placement has long been experimented in rice-producing countries. Several field studies with labelled urea ( $15 \mathrm{~N}$ isotope) have permitted to understand how the fate of the fertilizer nitrogen $[1,2]$ was considerably improved by deep placement of urea supergranules (USG) between 7 and $10 \mathrm{~cm}$. The optimal mass of the USG is $2 \mathrm{~g}$ or $3 \mathrm{~g}$ if it is deep placed between four hills of transplants in the classical $20 \mathrm{~cm}$ by $20 \mathrm{~cm}$ geometry of transplanting [1,3]. Each hill consists of three or four seedlings.

A higher density of USGs (one USG at $12 \mathrm{~cm}$ depth and $3-5 \mathrm{~cm}$ away from each hill, mass of USG being $1-1.5 \mathrm{~g}$ ) is sometimes practiced to enhance the level of applied urea. This method is known as root zone fertilization [4].

Whatever the positioning of the USG, an important issue is how ammonia formed in just a few days after the urea application is diffusing within the soil. The question is both practical and theoretical [3]. Practically, how do you

Rémi Gaudin, remi.gaudin@supagro.fr | ${ }^{1}$ CIRAD, INRAE, ABSys, Univ Montpellier, Institut Agro, 2 place Viala, 34060 Cedex 2 Montpellier, France. ${ }^{2}$ Laboratoire des Radio-Isotopes, BP. 3383, 101 Antananarivo, Madagascar. 
characterize and measure ammonia distribution varying from levels (at 4 days after placement) as high as $0.3 \mathrm{M}$ (in soil solution) at the application point (of $2 \mathrm{~g}$ USG) to near zero at less than $7 \mathrm{~cm}$ from this point? Theoretically, urea and ammonia deriving from the USG are solutes obeying the classical law of diffusion. Moreover, the soil is watersaturated. This condition simplifies the diffusion equation because it limits the variation of one important factor affecting the diffusion coefficient, namely the soil water content.

In previous works, we combined a description of the soil solution content by the diffusion equation and a method for soil solution obtention. This approach combining the theory of diffusion and soil solution monitoring is again mobilized in this paper, but this time we shall take into account the perturbative effect of ammonia exchange within the paddy soil.

An important term in nitrogen dispersion from deepplaced urea in paddy soils is the exchange of ammoniacal nitrogen between the soil solution and the soil matrix, more precisely between the soil solution and the organic matter and clay contents of the soil. If the soil was only sand, the analytical solution of the ammoniacal nitrogen diffusion equation would be true, except for the initial urea hydrolysis phase. In a real soil, the diffusion process occurs less quickly because of the slowdown effect brought on by the exchange of ammonium on the negative sites of clay and humic substances. In this paper, we are proposing a numerical treatment of this diffusion-exchange process. The initial phase of urea hydrolysis is considered to be short enough to separate it from the core of our problem, the calculation of diffusion-exchange.

We have a lot of data showing rapid urea hydrolysis in the case of USG application, and we shall discuss the implications of these data after presentation of the model and its applications in various laboratory and field conditions.

This model is a first attempt to describe a complex phenomenon in the field of fertilizer research, namely the nitrogen dispersion from a deep placed point source in the anaerobic layer of a paddy soil. We shall also discuss how this model could evolve to study new fertilizers.

\section{Material and methods}

\subsection{Experiments}

The diffusion experiments were performed using tanks placed in a dark room of Laboratoire des Radio-Isotopes (denoted LAB), Antananarivo (Madagascar). They were followed by one experiment performed in a rice field near the town of Arivonimamo (denoted ARIVO), West of Antananarivo. The $L A B$ experiment used the upper horizon
$(0-30 \mathrm{~cm})$ of the paddy soil of ARIVO. This soil has the following characteristics: $40 \%$ clay, $27 \%$ silt, $33 \%$ sand, and $2.3 \%$ organic matter. The predominant mineral in the clay fraction is kaolinite.

The temperature in $\mathrm{LAB}$ experiments was set at $25^{\circ} \mathrm{C}$. A first experiment (array laboratory experiment) was dedicated to the study of ammonia diffusion from the USG $(2 \mathrm{~g}$ mass) in saturated conditions such as those encountered in the natural environment. The soil solution water content was $0.60 \mathrm{~cm}^{3} \mathrm{~cm}^{-3}$, and the corresponding apparent density (for corresponding dry soil) was 1 . Samplers were placed on the same plane at $15 \mathrm{~cm}$ deep in order to measure ammonia at distances of 5-10 and $15 \mathrm{~cm}$ from the placement site (Fig. 1). Each sampler, a porous ceramic cup from Soilmoisture Equipment Corporation (Golota, California) has its hemispheric end oriented towards the USG application point. A manual vacuum pump was used in order to displace a few $\mathrm{mL}$ soil solution from soil around sampler(s) to the penicillin flask(s) (Fig. 1 and 2). Urea and ammonia were measured in the soil solution extracts, using colourimetric methods (respectively, diacetyl-thiosemicarbazide and indophenol blue methods). Soil solution sampling was practiced at 14,28 and $56 \mathrm{~d}$.

In the second LAB experiment, three other tanks were managed independently from the tanks with the array of samplers. They were prepared in the same way (same soil, same temperature, and same soil water content). For each tank, one single soil ceramic sampler [3] was placed in contact with a 2 g-USG (Fig. 2) and placed at $15 \mathrm{~cm}$ depth. Soil solution sampling was practiced at the following times: 4-7-11-18-25-32-40-48-56-64 d. Ammonia was determined by the same colourimetric method.

To obtain the adsorption isotherm, we put $1 \mathrm{~kg}$ of dry soil in boxes with individual volume of one L. We saturated them with $0.5 \mathrm{~L}$ of urea solutions with the following concentrations: $M, M / 5, M / 20, M / 50, M / 500,0$ plus distilled water. No air remained. The boxes were hermetically closed and incubated during one week at $25^{\circ} \mathrm{C}$. A ceramic cup (and manual vacuum pump) was then used to sample the soil solution. We verified full disappearance of urea (colourimetric determination by the diacetyl-thiosemicarbazide method), and we measured the soil solution ammonia concentration which is $c$ (indophenol blue method). Clay mineral being kaolinite (no ammonium retrogradation), we hypothesized that ammonia which was not in solution was adsorbed on the exchange matrix of the soil. This quantity $S$, adsorbed ammonia, is obtained by a balanced budget of nitrogen for each box (different concentration of added urea). The isotherm is the relation between $S$ and $c$.

In the field experiment (ARIVO), the floodwater depth was controlled either by runoff (over bunds or by managed openings in the bunds) in periods of active (sometimes 

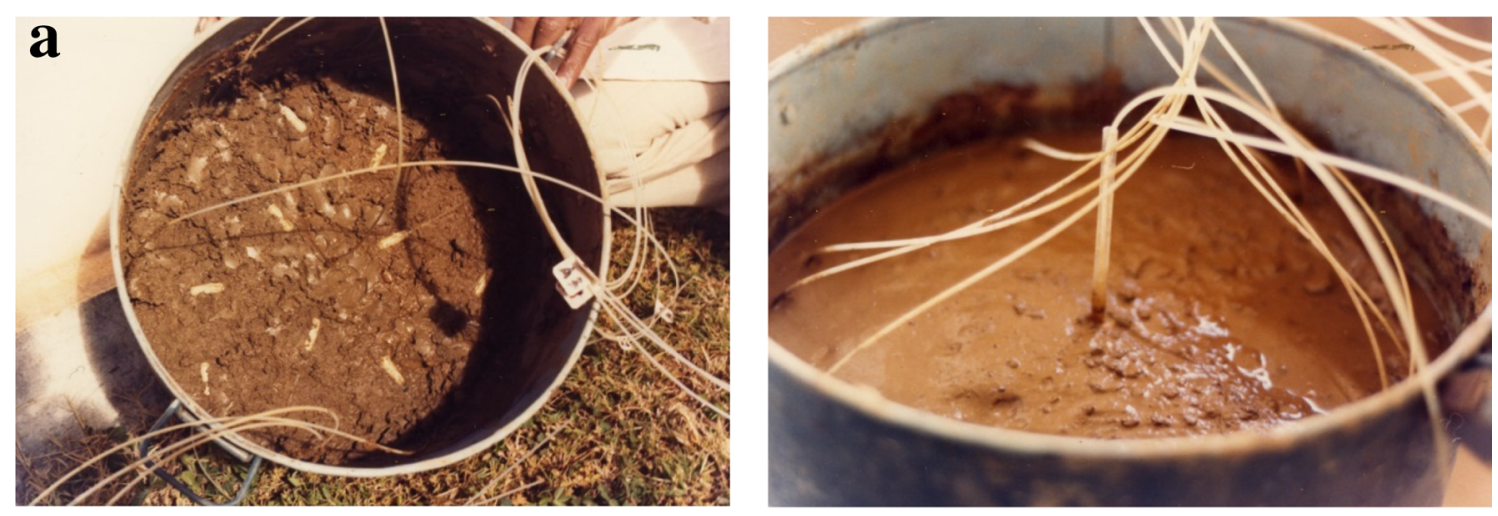

b

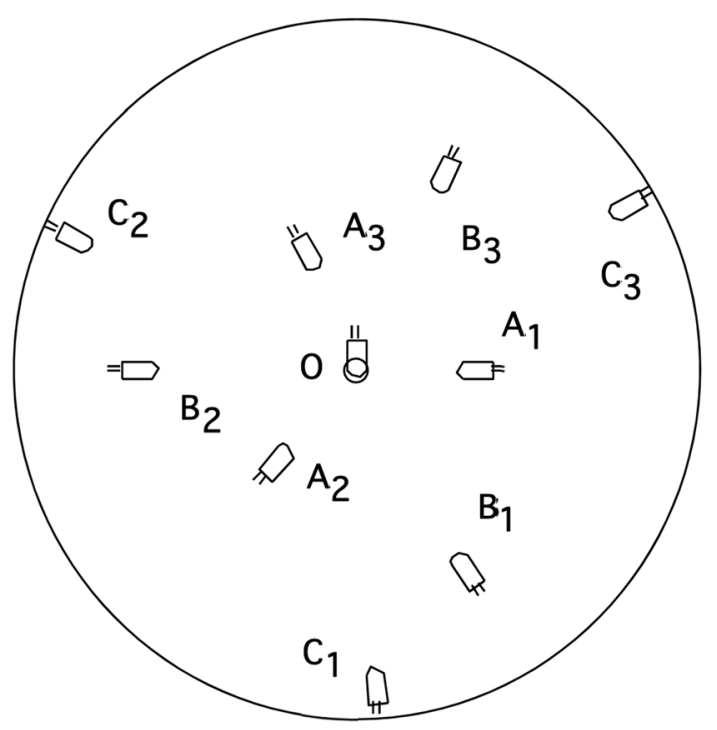

Fig. 1 Array of small ceramic cups for the study of ammoniacal nitrogen diffusion from a $2 \mathrm{~g}$ urea supergranule; a view before (left side) and after replacing the muddy soil (right side) on the plane of measurement. A small ceramic cup at the end of a glass rod (right) was descended at the centre of the plane one day before the first

sampling measurement. The left-side photograph has been taken when the experiment was finished in order to verify the positions of all samplers (the central sampler is in vertical position); b sketch giving the relative distances to $O$ (central position) for the A-B-C series of samplers ( $5 \mathrm{~cm}$ for $\mathrm{A}, 10 \mathrm{~cm}$ for $\mathrm{B}$ and $15 \mathrm{~cm}$ for $\mathrm{C}$ )

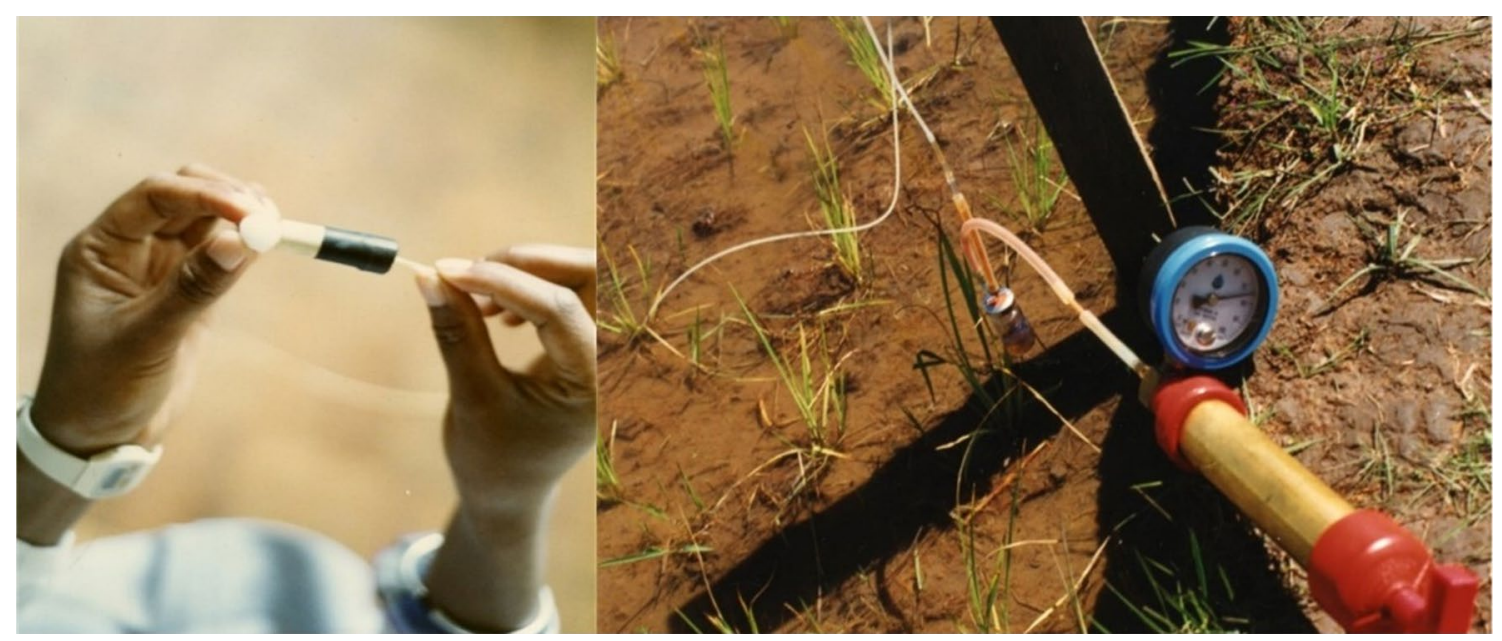

Fig. 2 View of a $2 \mathrm{~g}$ USG put in contact with the soil ceramic sampler (left) and view of the nylon tube, penicillin flask and manual vacuum pump (right) used to draw the soil solution into the flask (field experiment) 
successive) storms or by an added contribution from the nearby river to maintain if necessary the saturated status of the field. The transplanting geometry was $20 \mathrm{~cm}$ by $20 \mathrm{~cm}$. Ceramic samplers, porous ceramic rods from Soilmoisture Equipment Corporation (Golota, California), were placed in contact with the $2 \mathrm{~g}$ USGs by their flat bottoms (Fig. 2). The dimensions of each sampler were as follows: active length $15 \mathrm{~mm}$, diameter $12.5 \mathrm{~mm}$, wall thickness $2 \mathrm{~mm}$. Six samplers were used. The soil solution was drawn off (Fig. 2) and collected at 4-13-24-31-41-52-55 and $59 \mathrm{~d}$ after transplanting and fertilization. This was analysed for ammoniacal nitrogen and for urea.

\subsection{Diffusion and exchange model}

Urea being very soluble in soil solution and urea hydrolysis being near complete after less than 1 week in transplanted paddy soils, we have chosen to separate the diffusional processes of the disappearing urea and of the generated ammonia and to introduce a short transition phase for hydrolysis. By applying this virtual approach during the first days after USG placement, we limit the number of variables and parameters and we facilitate the numerical calculation of nitrogen diffusion. To treat the problem of diffusion for the urea and ammonia in a concomitant way would require a lot of information on parameters affecting urea hydrolysis which would be difficult to assess because the urease present in paddy soil is not unique but rather a mixture resulting from the action of various microorganisms or rice roots.

We have considered the USG (if properly placed around $8 \mathrm{~cm}$ into the anaerobic layer of the soil) as an instantaneous and point source of nitrogen diffusing in an infinite medium. The main parameter is the quantity of $\mathrm{N}$ delivered by the source. For a $2 \mathrm{~g}$ USG it is $66,666 \mu$ moles of $\mathrm{N}$. After the rapid dissolution of the USG (around a few hours according to [1]; less than half a day from our observations), the model is based on three separate phases:

- Phase I. A period of a few days, the diffusion process is assumed to concern urea alone and to occur within the soil solution. No urea is adsorbed on the organic matter or on the clay of the soil.

- Phase II. At a fixed time T, a very short transition is introduced for the hydrolysis of all urea into bicarbonate and ammonia. Part of the ammonia is instantaneously adsorbed on the soil matrix according to the adsorption isotherm obtained by experiment (previous section).

- Phase III. The ammoniacal-N is diffusing and exchanging within the soil.
In phase I, the diffusion equation [Eq. (1)] has an analytical solution [Eq. (2)] if we admit first spherical symmetry for the diffusion process, and secondly the mathematical representation of the USG as a point and instantaneous source.

$\mathbf{d} c_{\mathrm{u}} / \mathbf{d} t=D_{\mathrm{u}}\left[\left(2 / r \mathbf{d} c_{\mathrm{u}} / \mathbf{d} r\right)+\mathbf{d}^{2} c_{\mathrm{u}} / \mathbf{d} r^{2}\right]$

$C_{\mathrm{u}}(r, t)=\left(M_{\mathrm{u}} / 8 \theta\right)\left(\pi D_{\mathrm{u}} t\right)^{-3 / 2} \exp \left(-r^{2} / 4 D_{\mathrm{u}} t\right)$

with d, derivative operation; $M_{\mathrm{u}}$ quantity of urea- $\mathrm{N}$ in the source; $\theta$, volumetric soil water content $\left(\mathrm{cm}^{3} \mathrm{~cm}^{-3}\right) ; D_{\mathrm{u}^{\prime}}$ diffusion coefficient for urea $\left(\mathrm{cm}^{2}\right.$ day $\left.^{-1}=\mathrm{cm}^{2} \mathrm{~d}^{-1}\right) ; r$, distance to central position (point-position of the centre of USG) (in cm); $c_{\mathrm{u}^{\prime}}$ urea-N soil solution concentration.

In phase III, the diffusion-adsorption equation is written as:

$\left[1+(\rho / \theta) \mathbf{d} S / \mathbf{d} c_{\mathrm{a}}\right] \mathbf{d} c_{\mathrm{a}} / \mathbf{d} t=D_{\mathrm{a}}\left[\left(2 / r \mathbf{d} c_{\mathrm{a}} / \mathbf{d} r\right)+\mathbf{d}^{2} c_{\mathrm{a}} / \mathbf{d} r^{2}\right]$

with $\rho$, apparent density of dry soil; $D_{a^{\prime}}$ diffusion coefficient for ammonia $\left(\mathrm{cm}^{2}\right.$ day $\left.{ }^{-1}=\mathrm{cm}^{2} \mathrm{~d}^{-1}\right) ; c_{\mathrm{a}^{\prime}}$ ammonia-N soil solution concentration; $S$, adsorbed ammonia.

With the adsorption isotherm being a Freundlich isotherm, $S=k\left(c_{\mathrm{a}}\right)^{n}$, Eq. (3) becomes:

$\left[1+(\rho / \theta) k n c_{\mathrm{a}}^{n-1}\right] \mathbf{d} c / \mathbf{d} t=D_{\mathrm{a}}\left[\left(2 / r \mathbf{d} c_{\mathrm{a}} / \mathbf{d} r\right)+\mathbf{d}^{2} c_{\mathrm{a}} / \mathbf{d} r^{2}\right]$

To solve this equation, we used the algorithm developed in Appendix. It is based on the Crank-Nicholson [5] method for differentiation and a method of numerical calculation described in Richtmyer and Morton [6]. The time step was taken at $0.0625 d$, and the radius step was taken at $0.25 \mathrm{~cm}$. The duration of phase I was $T=5 \mathrm{~d}$ (first round of calculation) or $3 \mathrm{~d}$ (second round of calculation). The diffusion coefficient was set at $0.547 \mathrm{~cm}^{2} \mathrm{~d}^{-1}$ for the calculation, which could represent well the situation in soils with high clay content.

In a saturated soil, the diffusion coefficient of a solute s is defined by the classical relation $[7,8]$ :

$D_{\mathrm{s}}=\left(D_{\mathrm{o}}\right)_{\mathrm{s}} \theta \zeta$

With $\left(D_{\mathrm{o}}\right)_{s^{\prime}}$ the diffusion coefficient of solute $s$ in pure water; $\theta$, the volumetric water content of the soil, $\zeta$, the tortuosity factor (smaller than unity) expressing 'the ratio of the straight line length of a soil sample to the average roundabout path length through the water-filled pores for the diffusing molecule or ion' [7]. As explained by Hillel, the tortuosity factor is the inverse of the tortuosity, which is between 1 and 2 .

For the diffusion coefficient of urea and ammoniacal nitrogen into pure water, we have retained the values 
of $1.19 \mathrm{~cm}^{2} \mathrm{~d}^{-1}$ [9] and $1.52 \mathrm{~cm}^{2} \mathrm{~d}^{-1}$ [10], respectively. The volumetric water content was set at $0.6 \mathrm{~cm}^{3} \mathrm{~cm}^{-3}$. Five values of the tortuosity factor were considered, $0.65-0.70-0.75-0.80-0.85$. The numerical calculus was performed at week intervals with a unique diffusion coefficient of $0.547 \mathrm{~cm}^{2} \mathrm{~d}^{-1}$. Time correspondences were established to take into account differences in soil tortuosity (and consequently in the diffusion coefficients). The reason is that the ammonia distribution (at the end of any week) corresponding to a value of $\zeta_{1}$ say $\zeta_{2}$ as a second value (for example), is the same as the ammonia distribution for a first value $\zeta_{1}$, but at a different time because the operation generated by the diffusion equation (using $D$ calculated with the $\zeta_{2}$ value) corresponds to a homothetic time translation by the ratio $\zeta_{1} / \zeta_{2}$ (relatively to the diffusion and $D$ calculated with the $\zeta_{1}$ value). For example, let us choose $\zeta_{2}=1.1 \zeta_{1} ;$ in that case, $D_{2}>D_{1}$. The diffusive effect obtained in 1 week with $\zeta_{1}$ will be obtained with $\zeta_{2}$ in 1 week multiplied by $\zeta_{1} / \zeta_{2}$ because:

$\left(D_{\mathrm{s}}\right.$ time 1 week $)=\left(D_{\mathrm{o}}\right)_{\mathrm{s}} \theta \zeta_{1}$ time 1 week $=\left(D_{\mathrm{o}}\right)_{\mathrm{s}} \theta\left(\zeta_{1} / \zeta_{2}\right)$ $\zeta_{2}$ time 1 week $=\left(D_{\mathrm{o}}\right)_{s} \theta \zeta_{2}$ time 1 week divided by $\zeta_{2} / \zeta_{1}$

In that case where $\zeta_{2}>\zeta_{1}$ (equivalent to $D_{2}>D_{1}$ ), the same result is obtained in less time.

In experiments with replications, the tortuosity factor was approached by comparison of calculation and experimental results for various values of the tortuosity factor. In the array laboratory experiment where the diffusion process was scrutinized 14, 28 and $56 \mathrm{~d}$ after USG installation, the tortuosity factor was similarly approached by comparing observations and the calculated time course of ammonia concentration for $\mathrm{O}$ and $\mathrm{A}$ positions (Fig. 1b).

\subsection{Statistical analysis}

The quality of the prediction was assessed through the coefficient of determination [11] defined as:
$\Sigma_{j} 4 \pi r_{j}^{2} \Delta r\left(\theta c_{j}+\rho S_{j}\right)$

with $r_{j}=j \Delta r$, distance to central point; $\Delta r$, space radial step, selected at $0.25 \mathrm{~cm} ; c_{j}$ and $S_{j}$, calculated ammoniacal $N$ concentration and adsorbed ammoniacal $N$ at distance $r_{j}$.

The quantity defined by Eq. (7) is expected to be near equal to $M_{\mathrm{u}}$ quantity of $N$ in the source ( $2 \mathrm{~g}$ USG).

\section{Results}

\subsection{Exchange isotherm}

The exchange isotherm (Fig. 3) has a main branch and two secondary branches. The main branch is valid from $2.47 \mathrm{mM}$ to $1 \mathrm{M}$ ammoniacal $N$ concentration; it is a Freundlich isotherm with $1 / 2$ as exponent $n$. Exponents in minor branches are 1 and 2 .

In the main branch, we can assess with the equation reported in Fig. 3 the relative importance of ammoniacal- $\mathrm{N}$ in soil solution $(\theta c)$ and ammoniacal- $\mathrm{N}$ adsorbed on soil $(\rho S)$. The two are equal for $c=0.35 \mathrm{M}$. Above this value (just after urea hydrolysis in the central zone), there is more ammonia in the soil solution than in the adsorbed position. Below this value, $0.1 \mathrm{M}$ for example, there is more ammoniacal- $\mathrm{N}$ in the adsorbed position $\left(0.112 \mathrm{~mol} \mathrm{dm}^{-3}\right.$ soil) than in the soil solution $\left(0.06 \mathrm{~mol} \mathrm{dm}^{-3}\right.$ soil). This trend is accentuated for decreasing concentrations.

In the second branch, the adsorbed part is always greater than the part in solution. The third branch applies only for very low concentrations of ammonia. At concentration around $0.04 \mathrm{mM}$, the two parts are again equal.

Coefficient of determination $=1.0-\left(\sum_{i=1}^{N}\left(O_{i}-\underset{i}{-}\right)^{2}\right) /\left(\sum_{i=1}^{N}\left(O_{i}-O_{m}\right)^{2}\right)$

with $O_{i}$ : observed data (log of ammonia concentration measurements), $O_{m}$ : mean value of $N$ observations, $P_{i}: \log$ of calculated ammonia concentrations (with the model).

Coefficient of determination approaching 1 signifies good to excellent quality.

The success of numerical calculation was assessed through verification of matter conservation. The quantity of ammoniacal $N$ was calculated 2 times ( 28 and $56 \mathrm{~d}$ ). It is given by the sum of $N$ quantities present in the successive shells, all with thickness equal to $\Delta r$, beginning at $r=0$ and ending at a distant point (here $20 \mathrm{~cm}$ ) where ammoniacal $N$ concentration is zero:

\subsection{Conservation of matter during the process of diffusion-exchange}

Comparatively to the mass of urea-N brought by a $2 \mathrm{~g}$ USG ( $66666 \mu$ moles of $N$ ), the calculated quantity of diffusing ammonia given by Eq. (7) was $99.71 \%$ of the initial mass at 28 days and $99.38 \%$ at 56 days. This is a clear indication that the time step $(0.0625 \mathrm{~d})$ and radius step $(0.25 \mathrm{~cm})$ were adequate for the numerical calculation.

The distribution of the ammoniacal- $\mathrm{N}$ changed with time. At 28 days, we found $13.5 \%$ of the initial mass in the $0-3-\mathrm{cm}$ interval (in a sphere with $3 \mathrm{~cm}$ radius), $33.8 \%$ in the 


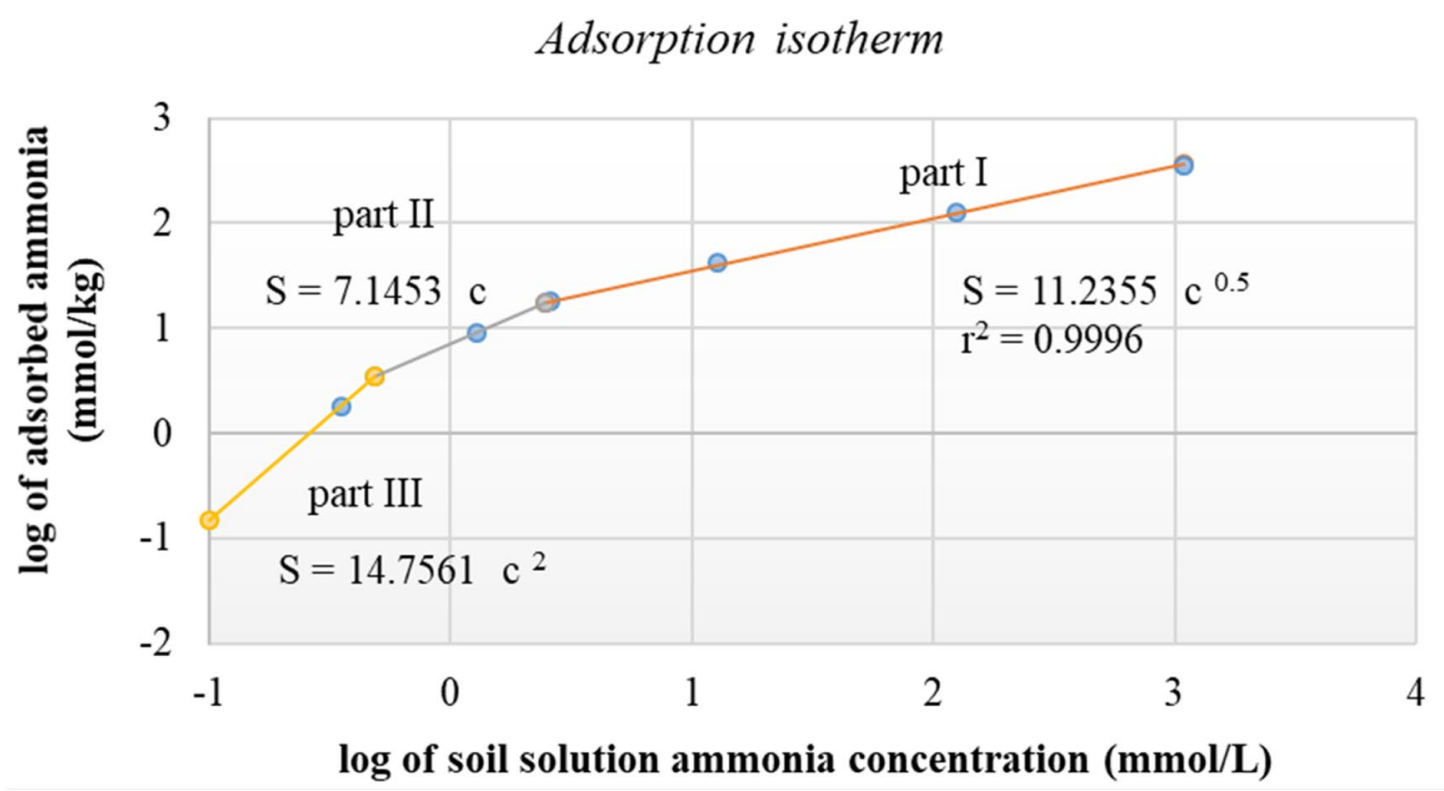

Fig. 3 Relation between the quantity of adsorbed ammonia -S- and the ammonia soil solution concentration -c-. Results are the main branch of a Freundlich isotherm (part I) and two minor branches (II and III). Equations given on the graph

Table 1 Model coefficient of determination for various values of the tortuosity factor (LAB experiment)

\begin{tabular}{llllll}
\hline Tortuosity factor & 0.65 & 0.70 & 0.75 & 0.80 & 0.85 \\
\hline Model $\left(T^{*}=5 \mathrm{~d}\right)$ & 0.9064 & 0.9464 & 0.9728 & 0.9815 & 0.9771 \\
Model $(T=3 \mathrm{~d})$ & 0.9330 & 0.9652 & 0.9807 & 0.9824 & 0.9549 \\
\hline
\end{tabular}

${ }^{*} T$ is duration of phase I. In the model, phase I corresponds to urea diffusion alone. Hydrolysis (phase II) ends this phase I

3-5-cm interval, $39.6 \%$ in the $5-7-\mathrm{cm}$ interval and $11.5 \%$ in the $7-9-\mathrm{cm}$ interval. At 56 days, the percentages were $8.5,24.0,36.3$ and 24.9 in the same intervals.

\subsection{LAB experiment with single sampler attached to the USG}

Two parameters, the tortuosity factor, $\zeta$, and the duration of urea diffusion, $T$, were given independent values to make runs of the model. $T$ was $3-5 \mathrm{~d}$, and $\zeta$ was $0.65-0.70-0.75-0.80-0.85$. Whatever the duration of phase $\mathrm{I}$, the maximal coefficient of determination of the model in predicting the observed data was high: 0.9815 and 0.9824 (Table 1). In both cases ( $3 \mathrm{~d}$ and $5 \mathrm{~d}$ ), it was attained for a tortuosity factor of 0.80 .

Graphically, a change of the tortuosity factor corresponds to a time translation of the theoretical prediction (Fig. 4).

\subsection{LAB experiment with array of samplers}

In the experiment with the array of samplers, the correspondence between observations and prediction was better with a tortuosity factor of 0.65 (Fig. 5b) than with a tortuosity factor of 0.80 (Fig. 5a). However, the superposition of experimental points on the theoretical curve was not observed in all positions of the samplers, as they are noted in Fig. 1. Good superposition was obtained by the central $O$ sampler and the $A 2$ sampler at $5 \mathrm{~cm}$.

A very small amount of ammoniacal- $\mathrm{N}$ has diffused at $10 \mathrm{~cm}$ distance, at $28 \mathrm{~d}, 0.17 \mathrm{mM}$ for the mean of values obtained in B1-B2-B3 position (versus $0.11 \mathrm{mM}$ predicted by the model). No ammoniacal-N has diffused at $15 \mathrm{~cm}$ distance.

\subsection{Field experiment}

As in $L A B$ experiment with a single sampler, a change of $T$ has little influence upon the prediction. The best fit is obtained with $5 \mathrm{~d}$ for this parameter and 0.80 for $\zeta$ (Table 2). Five replicates out of six give a coefficient of determination between 0.952 and 0.984 . Only for replicate 1 does the model coefficient of determination decrease to 0.870 or 0.846 . In this case, the ammonia concentration is decreasing faster than predicted by the model (Fig. 6).

In all replicates, we can observe that the diffusion-exchange process is separated from a process of a different nature occurring just after (Fig. 6). This second phenomenon has a first-order kinetics. This reflects ammonia disappearance plausibly driven by ammonia assimilation within the roots. The intersection of the diffusion-exchange curve with the straight line gives a distinctive value of ammonia concentration. It occurs at a moment where rice roots are coping with a locally 
Fig. 4 Comparison of experimental and theoretical values of ammonia concentration in the placement site of $2 \mathrm{~g}$ USG (LAB experiment). The curve (series 3 ) is indicative of a similar trend (near superposition) in experimental data and in the theoretical prediction with a tortuosity factor of 0.8

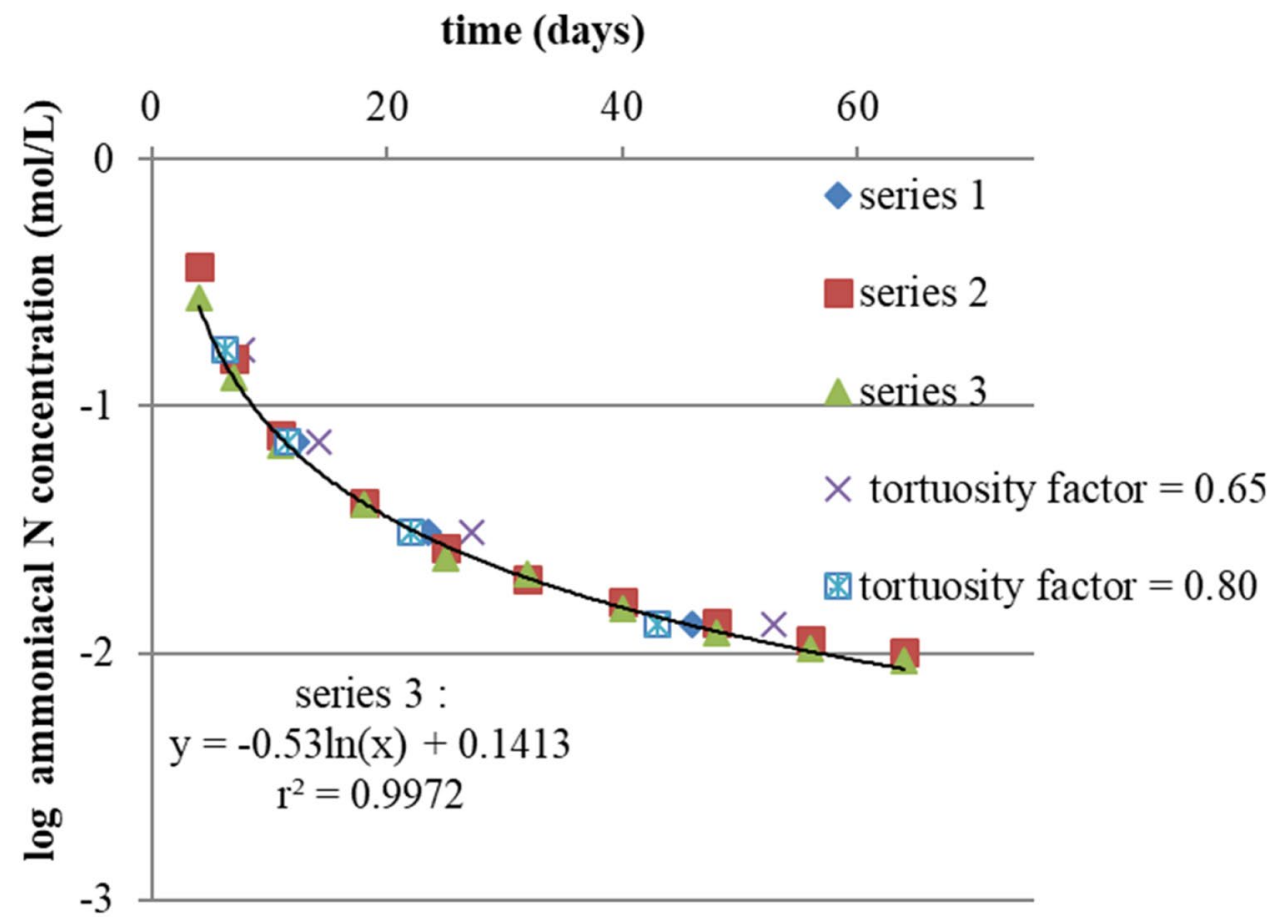

enriched environment. For 4 replicates, the result is $12 \mathrm{mM}$ ammoniacal-N (Table 3 ) and this concentration is attained by the diffusion-exchange process at 38 or $39 \mathrm{~d}$ for the ARIVO field.

\section{Discussion}

\subsection{Exchange isotherm}

The main exchange isotherm for ammoniacal- $\mathrm{N}$ was a Freundlich isotherm with $n=0.5$ as exponent. Similar or close values of $n$ have been found by Vogeler et al. [12], but other values have been reported in the literature, 0.66 [13] and $0.8-1.2$ [14]. The $1 / 2$ exponent gives an advantage in calculation (see in Appendix Eq. (15) giving the solution of Eq. (13)) because it permits an easy factorization of the second-order polynom that appears in the algorithm when urea- $\mathrm{N}$ is (in our model) instantaneously transformed into ammoniacal-N. The exponents of the secondary branches ( $n=1$ or 2 ) offer the same facility in the numerical calculation. However, a sub-program could be added to the algorithm for the general case of an exponent being a real number. The computer time needed to perform this task should be short in regard to the essential part of the algorithm.

The relative parts of ammoniacal- $\mathrm{N}$ in adsorbed position and ammoniacal- $\mathrm{N}$ in solution are important characteristics of the diffusion-exchange process. Because the term $(\theta c)$ is greater than the term $(\rho S)$ above $0.35 \mathrm{M}$ ammonia in soil solution, the diffusion process is only a little disturbed by the exchange term in the first days after USG placement and urea hydrolysis. By contrast week (s) later the adsorbed ammonia being largely greater than the ammoniacal- $\mathrm{N}$ in soil solution, this unbalance has a slowdown effect on the diffusive phenomenon.

\subsection{Experiment with array of samplers}

In central position (O sampler) and for one (A2) of the three samplers at $5 \mathrm{~cm}$ distance, the prediction was excellent. The $A 1$ and $A 3$ samplers gave near identical ammonia concentrations, but these were those predicted by the model for a distance of $6 \mathrm{~cm}$ from the central position (Fig. 5b). The simple interpretation is that these two samplers were displaced either by movement of the puddled soil in the installation or by pulling them (through unfortunate nylon tube movement) at the first withdrawal of soil solution samples.

The difference of tortuosity factor in the single sampler and array of sampler experiments is likely linked to differences in preparation of the saturated soil.

\subsection{Field experiment}

For one replicate, the coefficient of determination is less than for all other replicates. To explain this singular behaviour, we can imagine that the volumetric water content of the soil was higher around the corresponding sampler (replicate 1) than the value of $0.6 \mathrm{~cm}^{3} \mathrm{~cm}^{-3}$ retained in 
Fig. 5 Comparison of ammonia concentrations in positions $\mathrm{O}$ and $A$ with predictions by the model of diffusion-exchange, for a tortuosity factor of 0.80 in $\mathbf{a}$ and 0.65 in $\mathbf{b}$
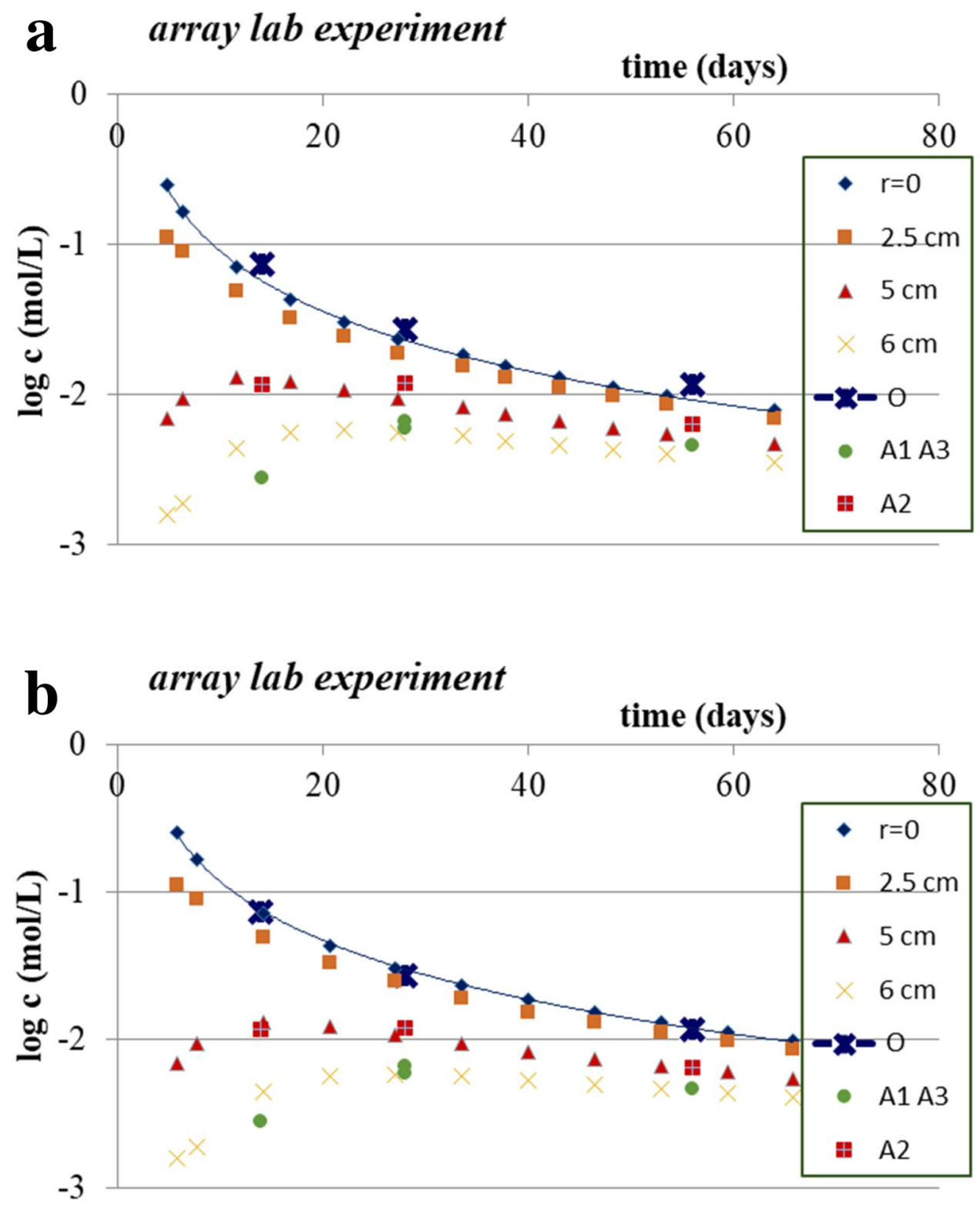

Table 2 Model coefficient of determination for replicates of ARIVO experiment. Calculus with the tortuosity factor set at 0.80

\begin{tabular}{llllllll}
\hline Replicate & 1 & 2 & 3 & 4 & 5 & 6 & mean \\
\hline Model $(T=5 \mathrm{~d})$ & 0.8699 & 0.9713 & 0.9685 & 0.9837 & 0.9593 & 0.9517 \\
Model $(T=3 \mathrm{~d})$ & 0.8464 & 0.9670 & 0.9712 & 0.9767 & 0.9715 & 0.9561 & 0.94807 \\
\hline
\end{tabular}

all our calculations. This means that the preparation of the soil was not completely homogeneous in the field. Its origin would imply spatial differences in the intensity of puddling.

The temporal separation of the physical and biological processes, first diffusion-exchange, secondly ammonia assimilation, is the main property displayed by the USGrice system when it is observed near the central position $O$ (application point) $[15,16]$. It occurs at $12 \mathrm{mM}$ ammoniacal-N. A higher level (13.7 mM) with slightly alkaline condition ( $\mathrm{pH}$ 7.85) had been determined in previous research on another site in Madagascar [17], but the separation had occurred later, at 45 or $46 \mathrm{~d}$, probably due to differences in the field tortuosity or other factors (parameters of the Freundlich isotherm). 

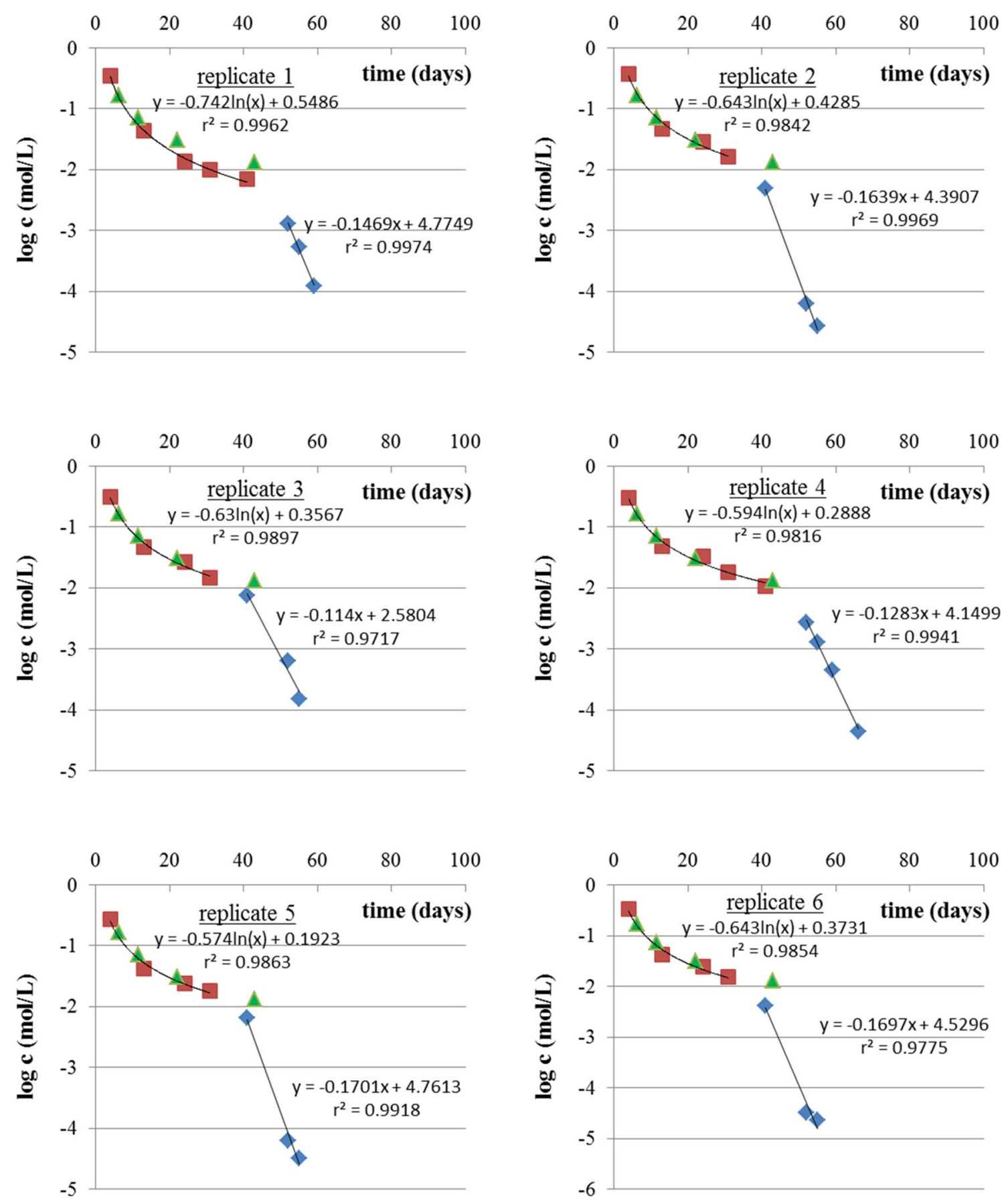

Fig. 6 Contribution of diffusion-exchange (rectangles) and assimilation (blue diamonds) to the disappearance of ammoniacal $\mathrm{N}$ in the placement site of $2 \mathrm{~g}$ USG (ARIVO experiment). Green triangles for the diffusion-exchange model with a tortuosity factor of 0.8

Table 3 Coordinates of the point where the diffusionexchange curve intersects the straight line reflecting the first-order kinetics of ammonia assimilation

\begin{tabular}{|c|c|c|c|c|c|c|c|c|}
\hline Replicate & 1 & 2 & 3 & 4 & 5 & 6 & Interval for 2-3-5-6 & Mean \\
\hline Date (d) & 48.37 & 38.49 & 39.095 & 48.02 & 39.245 & 38.31 & $38.31-39.245$ & 38.785 \\
\hline $\begin{array}{l}\text { Ammoniacal-N } \\
\text { concentration } \\
\text { (mM) }\end{array}$ & 4.68 & 12.07 & 13.29 & 9.75 & 12.21 & 10.68 & $10.68-13.29$ & 12.06 \\
\hline
\end{tabular}


At this level of ammonia concentration (12 mM), the part of $\mathrm{NH}_{3}$ in the ammoniacal- $\mathrm{N}$ can be a few percent, raising questions on avoidance of ammonia toxicity by roots and associated stopping of elongation growth. Jiao et al. [18] have recently elucidated the molecular mechanisms of root growth elongation inhibition acting just in the top range of ammoniacal- $\mathrm{N}$ concentration found in this study. The roots in the enriched central zone have very likely attained a stationary state. It is also well known from plant physiologists that ammonia assimilation has priority over other biochemical processes (ammonia being 'considered' a rare resource by plants). As ammonia assimilation requires oxo-glutarate $(=a$-ketoglutarate) and reductant power [19-21], it seems plausible that some biochemical signal(s) and/or molecular regulation had triggered an anaplerotic reaction which at the carbon-nitrogen interface supplies sufficient oxo-glutarate as substrate to the ammonia assimilation cycle. Then, the straight lines encompassing 12-0.1 $\mathrm{mM}$ in ammonia concentration (38-55 DAF- days after fertilization-in Fig. 6) can be in fact the kinetic signature of $C$ skeleton furniture to the ammonia assimilation cycle $[16,22]$. This interpretation is supported by a $15-\mathrm{N}$ experiment performed in the same field to document the kinetics of nitrogen uptake. Nitrogen recovery (aerial parts) was $9.8 \%$ at $32 \mathrm{DAF}, 41.8 \%$ at 52 DAF and $60.7 \%$ at 73 DAF [23]. So ammonia disappearance from soil solution ( $39 \mathrm{~d}$ to $55 \mathrm{~d}$ ) has the same kinetics as nitrogen uptake and assimilation.

\subsection{Influence of urea diffusion duration}

Urea hydrolysis is a dynamic phenomenon. After urea deep placement, it occurs in parallel with diffusion. A direct consequence of urea hydrolysis is an increase in $\mathrm{pH}: \mathrm{pH} 9$ has been measured $3 \mathrm{~d}$ or $4 \mathrm{~d}$ after application $[1,17]$. At this maximum $\mathrm{pH}$ value, all of the urea was not hydrolyzed. In ARIVO field experiment, we found between 0.023 and $0.041 \mathrm{M}$ urea- $\mathrm{N}$ at $4 \mathrm{~d}$ and between 0.002 and $0.003 \mathrm{M}$ at $13 \mathrm{~d}$. The mean ammoniacal- $\mathrm{N}$ concentration was $0.324 \mathrm{M}$ at $4 \mathrm{~d}$. In the array $L A B$ experiment, we found $0.003 \mathrm{M}$ urea$\mathrm{N}$ in $\mathrm{O}$ position and less than $0.001 \mathrm{M}$ in A position $(5 \mathrm{~cm})$ at $14 \mathrm{~d}$. The reasons for persistence of residual urea can be the inhibition of urease by high concentrations of urea [8] and the influence of enhanced alkalinity on urease activity $[9,24]$.

Modelling these factors would require several independent experiments and many parameters. The main reason is that urease is not a unique molecule but a mixture of molecules [25], each with its origin (rice roots, urease adsorbed on clay particles, etc.), rate of production and kinetics of action modified by environmental factors.

In our model, a single parameter ( $T$ ) was used. In fact, this parameter has a moderate influence on the diffusion of ammoniacal-N. Ammonia concentrations are slightly heightened for $T=3 \mathrm{~d}$, relatively to the values obtained for $T=5 \mathrm{~d}$ (Fig. 7). The choice $T=3 \mathrm{~d}$ could apply for the case of $N$ applied weeks after transplanting (urease deriving from roots adds to urease adsorbed on clay minerals or produced by soil microbes) when the value $T=5 \mathrm{~d}$ seems satisfactory when $N$ deep placement is performed at rice transplanting.

\section{Conclusion}

In this study, we have applied the classical law of diffusion-exchange to the question of urea supergranule deep placement in transplanted rice cultivation. Our approach
Fig. 7 Influence of urea diffusion duration ( $3 \mathrm{~d}$ vs $5 \mathrm{~d}$ ) on time course of ammonia concentration for distances of $0 \mathrm{~cm}, 5 \mathrm{~cm}$ and $6 \mathrm{~cm}$. The tortuosity factor is 0.8 as in field experiment

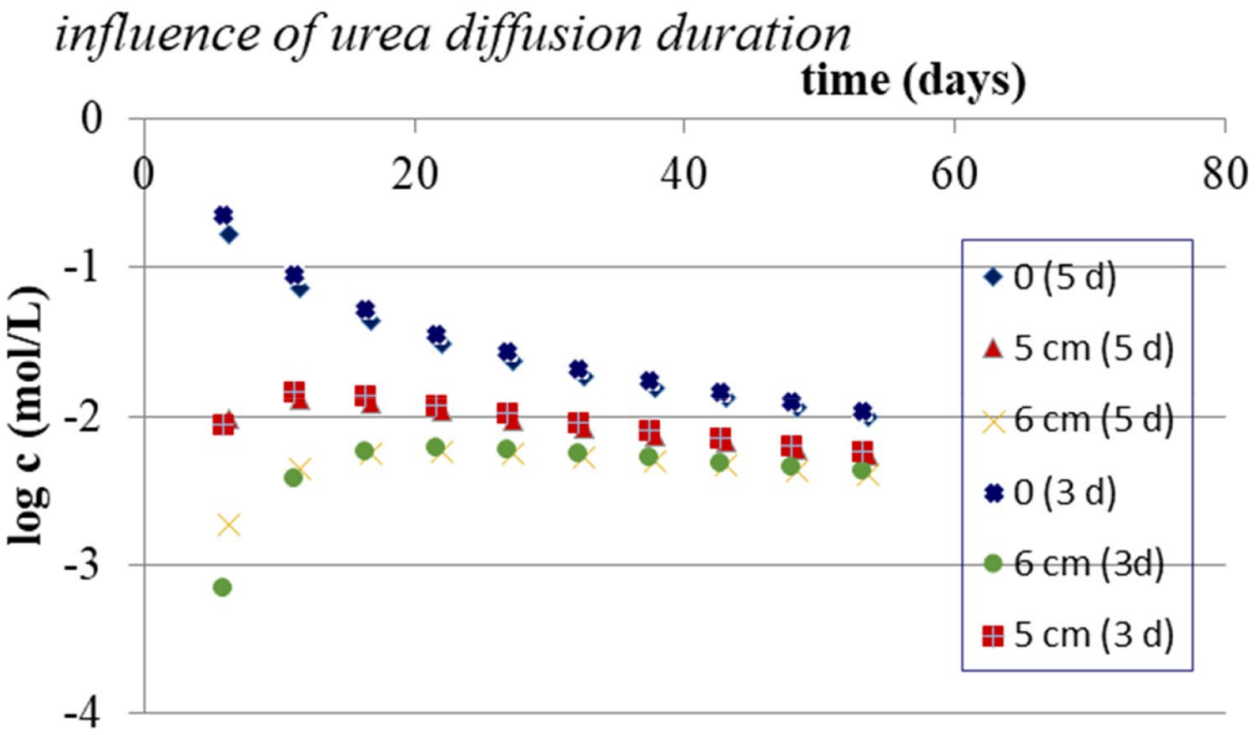


has required acquisition of data in laboratory and field experiments, and a special algorithm (respecting the spherical symmetry of the problem) to run the model.

The main result is that the tortuosity factor of the paddy soil is an essential parameter in the speed of the diffusion process. Changing the tortuosity factor leads to a time translation (with a homothetic factor equal to the ratio of tortuosity factors) in the graphical representation of the model output.

Another remarkable result in the field experiment is the independence of the two processes (after rapid urea hydrolysis), first diffusion-exchange in agreement with the model prediction, and secondly the ammoniacal- $\mathrm{N}$ assimilation process exhibiting a first-order kinetics. The limit between the two is at $12 \mathrm{mM}$ ammoniacal- $\mathrm{N}$ soil solution concentration. Just at this value, the 'hidden part' of rice plants (roots) have adapted to their environment, presumably halting their growth [18] and mobilizing the maximum of $C$ resources to take advantage of the ammonia at their disposal. The kinetics of ammonia disappearance should be the trace, the signature of the mechanism(s) regulating the $C-N$ interface.

If the rice-urea supergranule has the quality of a model system for research, USGs are not a miraculous solution in all paddy field situations notably in fertile soils where very high yield is expected. Granules of large mass (4 g) are problematic. Other options exist, root zone fertilization (one USG application per rice hill), deep application of controlled-released urea compounds or new forms of fertilizer such as small urea rods. This last idea could be tested by a numerical engineering procedure presenting strong resemblance with this work.
To solve Eq. (4), we have used the beginning of the Taylor series:

$c_{j+1}=c_{j}+\Delta r(\partial c / \partial r)_{j}+1 / 2(\Delta r)^{2}\left(\partial^{2} c / \partial r^{2}\right)_{j}$

$c_{j-1}=c_{j}-\Delta r(\partial c / \partial r)_{j}+1 / 2(\Delta r)^{2}\left(\partial^{2} c / \partial r^{2}\right)_{j}$

Then approximately:

$(\partial c / \partial r)_{j}=\left(c_{j+1}-c_{j-1}\right) / 2 \Delta r$

$\left(\partial^{2} c / \partial r^{2}\right)_{j}=\left(c_{j+1}-2 c_{j}+c_{j-1}\right) /(\Delta r)^{2}$

with index $j$ designating a radius step.

We shall use a second index $i$ to designate the time step. Using the centred differentiation technique of Crank and Nicholson [5], we can write:

$\partial c / \partial t=\left(c_{j, i+1}-c_{j, i}\right) / \Delta t$

$\partial c / \partial r=\left(c_{j+1, i+1}+c_{j+1, i}-c_{j-1, i+1}-c_{j-1, i}\right) / 4 \Delta r$

$\partial^{2} c / \partial r^{2}=\left(c_{j+1, i+1}+c_{j+1, i}-2 c_{j, i+1}-2 c_{j, i}+c_{j-1, i+1}+c_{j-1, i}\right) / 2(\Delta r)^{2}$

Replacing $\mathbf{d c} / \mathbf{d t}, \mathbf{d} \mathbf{c}_{\mathrm{a}} / \mathbf{d r}$ and $\mathbf{d}^{2} c_{\mathrm{a}} / \mathbf{d} \mathbf{r}^{2}$ by $\partial c / \partial t, \partial c / \partial r$ and $\partial^{2} c / \partial r^{2}$ in Eq. (4), we obtain:

$\left(1+V_{j i}\right)\left(c_{j, i+1-} c_{j, i}\right)=[D \Delta t / 2 \Delta r]\left[(1 / r)\left(c_{j+1, i+1}+c_{j+1, i-} c_{j-1, i+1}-c_{j-1, i}\right)\right.$

$\left.+(1 / \Delta r)\left(c_{j+1, i+1}+c_{j+1, i}-2 c_{j, i+1-} 2 c_{j, i}+c_{j-1, i+1}+c_{j-1, i}\right)\right]$

with $V_{j i}=(\rho / \theta) k n\left(c_{j, i}\right)^{n-1}$.

We have: $r=j \Delta r r=\mathrm{j} \Delta r$.

whereof

$\left(1+V_{j i}\right)\left(c_{j, i+1}-c_{j, i}\right)=\left[D \Delta t / 2(\Delta r)^{2}\right]\left[((1 / j)+1)\left(c_{j+1, i+1}+c_{j+1, i}\right)-2 c_{j, i+1}-2 c_{j, i}+(1-1 / j)\left(c_{j-1, i+1}+c_{j-1, i}\right)\right]$

Acknowledgements The author thanks Samuel Randrianarison for his help in soil solution obtention. Thanks are also due to Olivier Rakotoson who has secured the access to Ankatso computer facility (Université de Madagascar) and to Elaine Bonnier (Institut Agro, Montpellier) for her contribution to the improvement of the English in this manuscript.

\section{Compliance with ethical standards}

Conflict of interest This manuscript has no conflict of interest.

\section{Appendix}

\section{The Algorithm Used for Calculation}

For easier reading, the subscript a has been omitted from $c_{\mathrm{a}}$. which can be written as:

$$
\begin{aligned}
& c_{j+1, i+1}(-((j+1) / j) \underline{\Delta})+c_{j, i+1}\left(2 \underline{\Delta}+1+V_{j i}\right) \\
& \left.\quad+c_{j-1, i+1}(-((j-1) / j) \underline{\Delta})=c_{j+1, i}((j+1) / j) \underline{\Delta}\right) \\
& \left.\quad+c_{j, i}\left(-2 \underline{\Delta}+1+V_{j i}\right)+c_{j-1, i}((j-1) / j) \underline{\Delta}\right)
\end{aligned}
$$

with $\underline{\Delta}=D \Delta t / 2(\Delta r)^{2}$.

This equation can be put in the following form:

$$
-W_{j} c_{j+1, i+1}+X_{j, i} c_{j, i+1}-Y_{j} c_{j-1, i+1}=Z_{j, i}
$$

with

$$
W_{j}=((j+1) / j) \underline{\Delta}
$$

$X_{j, i}=2 \underline{\Delta}+1+V_{j, i}$ 
$Y_{j}=((j-1) / j) \underline{\Delta}$

and $Z_{j, i}$ is the right-hand side of Eq. (8)

Richtmyer and Morton [6] give the solution of Eq. (9) in the form:

$c_{j, i+1}=E_{j, i} c_{j+1, i+1}+F_{j, i}$

with

$E_{j, i}=W_{j} /\left(X_{j, i}-Y_{j} E_{j-1, i}\right)$

$F_{j, i}=\left(Z_{j, i}+Y_{j} F_{j-1, i}\right) /\left(X_{j, i}-Y_{j} E_{j-1, i}\right)$

The condition at left limit $(r=0)$ is that for $t>0$, the concentration is maximum: $\mathrm{d} c / \mathrm{d} r=0$

This writes as:

$-\underline{\Delta} c_{1, i+1}+\underline{\Delta} c_{-1, i+1}=\underline{\Delta} c_{1, i}-\underline{\Delta} c_{-1, i}$

if we use an imaginary point at a radius time step distance from $r=0$ (Crank and Nicholson, 1947).

Let us write Eq. (8) in the following form:

$$
\begin{aligned}
& c_{j+1, i+1}(-\underline{\Delta} / j)+c_{j+1, i+1}(-\underline{\Delta})+c_{j, i+1}\left(2 \underline{\Delta}+1+v_{j, i}\right) \\
& \quad+c_{j-1, i+1}(\underline{\Delta} / j)+c_{j-1, i+1}(-\underline{\Delta})=c_{j+1, i}(\underline{\Delta} / j)+c_{j+1, i}(\underline{\Delta}) \\
& \quad+c_{j, i}\left(-2 \underline{\Delta}+1+v_{j, i}\right)+c_{j-1, i}(\underline{\Delta})+c_{j-1, i}(-\underline{\Delta} / j)
\end{aligned}
$$

We can see for $\mathrm{j}$ tending towards 0 that the terms of Eq. (11) are reappearing in the last equation so that we can simplify it to:

$$
\begin{gathered}
c_{1, i+1}(-\underline{\Delta})+c_{0, i+1}\left(2 \underline{\Delta}+1+V_{0, i}\right)+c_{-1, i+1}(-\underline{\Delta}) \\
=c_{1, i}(\underline{\Delta})+c_{0, i}\left(-2 \underline{\Delta}+1+V_{0, i}\right)+c_{-1, i}(\underline{\Delta})
\end{gathered}
$$

and then to (because $c_{1}=c_{-1}$ ):

$$
\begin{aligned}
& c_{0, i+1}=\left(2 \underline{\Delta} /\left(2 \underline{\Delta}+1+V_{0, i}\right)\right) c_{1, i+1} \\
& \quad+\left(1 /\left(2 \underline{\Delta}+1+V_{0, i}\right)\right)\left[c_{1, i}(2 \underline{\Delta})+c_{0, i}\left(1-2 \underline{\Delta}+V_{0, i}\right)\right]
\end{aligned}
$$

By reference to Eq. (10):

$E_{0, i}=2 \underline{\Delta} /\left(1+2 \underline{\Delta}+V_{0, i}\right)$

$F_{0, i}=\left[c_{1, i}(2 \underline{\Delta})+c_{0, i}\left(1-2 \underline{\Delta}+V_{0, i}\right)\right] /\left(1+2 \underline{\Delta}+V_{0, i}\right)$

The initial distribution at $T$ (second phase) $=l \Delta t$, that is for $i=l$, is fixed by the conservation equation:

$\left(\rho c_{j, l}+\theta S_{j, l}\right)=A_{j, l}$

with $A_{j, l}$ being the analytical solution of the diffusion equation without adsorption term:
$A_{j, l}=\left(M_{u} / 8 \theta\right)(\pi D T)^{-3 / 2} \exp \left[-(j \cdot \Delta r)^{2} / 4 D T\right]$

Equation (13) presents solutions if the Freundlich coefficient of the isotherm, $n$, is $1 / 2,1$ or 2 . For example, in the case $n=1 / 2$ (main branch of the isotherm, Fig. 2):

$c_{j l}=\left[2 \theta A_{j l}+\rho^{2} k^{2}-\rho k\left(\rho^{2} k^{2}+4 \theta A_{j l}\right)^{1 / 2}\right] / 2 \theta^{2}$

We know then $c_{0, l}$ and thus $\mathrm{E}_{0, l}$ and $\mathrm{F}_{0,1}$

These values of $E_{0 \prime}, F_{0 /}$ and $c_{j l}$ permit us to calculate $E_{j, l}$ and $F_{j, 1}$ through Eqs. (10a) and (10b) by increasing $j$. The condition at the right-hand side $(j=J)$ permits to write from Eq. (10):

$c_{J, l+1}=E_{J, l} c_{J, l+1}+F_{J, l}$ because $c_{J, l+1}=c_{J+1, l+1}$

Then: $c_{J, l+1}=F_{J, l} /\left(1-E_{J, l}\right)$

The $c_{j, l+1}$ values are deduced in a progressive way from $c_{J, l+1}$ by decreasing $j$.

When this part of the whole calculus is finished, all the operations are begun again with the next time step.

\section{References}

1. Savant NK, Stangel PJ (1990) Deep placement of urea supergranules in transplanted rice : principles and practices. Fertili Res 25:1-83

2. Dupuy J, D'Onofrio G, Gaudin R (1990) Etude à l'aide d'urée enrichie en $15 \mathrm{~N}$ de la fertilisation azotée du riz inondé à Madagascar. 1. Comparaison entre supergranules d'urée, perlurée et solution d'urée placés à $1 \mathrm{~cm}$ ou $10 \mathrm{~cm}$ de profondeur. L'Agron Trop 45:3-10

3. Gaudin R, Dupuy J (1999) Ammoniacal nutrition of transplanted rice fertilized with large urea granules. Agron J 91(1):33-36

4. Liu X, Wang H, Zhou J, Chen Z, Lu D, Zhu D, Deng P (2017) Effect of root zone fertilization on rice yield, uptake and utilization of macronutrient in lower reaches of Yangtze river, China. Paddy Water Environ 15:625-638

5. Crank J, Nicholson P (1947) A practical method for numerical evaluation of solutions of partial differential equations of the heat conduction type. Math Proc Camb Philos Soc 43:50-67

6. Richtmyer RD, Morton KW (1967) Difference method for initial value problems. Wiley, New-York, p 405

7. Hillel D (1980) Fundamental of soil physics. Academic Press, New York, $\mathrm{p} 413$

8. Shah SB, Wolfe M, Borggaard JT (2004) Simulating the fate of subsurface-banded urea. Nutr Cycl Agroecosyst 70:47-66

9. Rachhpal-Singh NPH (1984) The diffusion of urea, ammonium and soil alkalinity from surface applied urea. J Soil Sci 35:529-538

10. Li Y, Simunek J, Zhang Z, Jing L, Ni L (2015) Evaluation of nitrogen balance in a direct-seeded-rice field using Hydrus-1 D. Agric Water Manag 148:213-222

11. Little TM, Hills FJ (1978) Agricultural experimentation. Design and analysis. Wiley, New-York, p 350

12. Vogeler I, Cichota R, Snow VO, Dutton T, Daly B (2011) Pedotransfer functions for estimating ammonium adsorption in soils. Soil Sci Soc Am J 75(1):324-331

13. Racchpal-Singh NPH (1986) A model of ammonia volatilization from applied urea. II.Experimental testing. J Soil Sci 37:21-29 
14. Kaluarachchi JJ, Parker JC (1988) Finite element model of nitrogen species transformation and transport in the unsaturated zone. J Hydrol 103:249-274

15. Gaudin R (2012) The kinetics of ammonia disappearance from deep-placed urea supergranules (USG) in transplanted rice: the effects of split USG application and PK fertilizer. Paddy Water Environ 10(1):1-5

16. Gaudin R (1993) Caractériser la fertilité des sols de rizière par une mesure à l'interface des métabolismes carboné et azoté de la plante: théorie, méthode et applications. In: Raunet M (ed) Bas-fonds et riziculture. Actes du séminaire d'Antanarivo, Madagascar, 9-14 décembre 1991. CIRAD, Montpellier, pp 305-312

17. Gaudin $\mathrm{R}$ (1988) L'ammoniac $\mathrm{NH}_{3}$, une clé pour comprendre l'efficacité des supergranules d'urée en riziculture repiquée. L'Agron Trop 43:30-36

18. Jiao $K$, Wang $H$, Kong $X$, Liu $Y$, Chu J, Chen $X$, Fang R, Yan $Y$ (2020) Promotion of BR biosynthesis by miR444 is required for ammonium-triggered inhibition of root growth. Plant Physiol 182:1454-1466

19. Lea PJ, Miflin BJ (2003) Glutamate synthase and the synthesis of glutamate in plants. Plant Physiol Biochem 41:555-564

20. Funayama K, Kojima S, Tabuchi-Kobayashi M, Sawa Y, Nakayama Y, Hayakawa T, Yamaya T (2013) Cytosolic glutamine synthetase $1 ; 2$ is responsible for the primary assimilation of ammonium in rice roots. Plant Cell Physiol 54:934-943
21. Yoneyama T, Tanno F, Tatsumi J, Mae Y (2016) Whole-plant dynamic system of nitrogen use for vegetative growth and grain filling in rice plants (Oryza sativa L.) as revealed through the production of 350 grains from a germinated seed over 150 days: a review and synthesis. Front Plant Sci 7:1151

22. Gaudin R (2015) Des modèles agronomiques pour comprendre, prévoir, intervenir. Exemples en zones tropicale et méditerranéenne. Université Paul-Valéry Montpellier, Habilitation à Diriger des Recherches/Research Direction Accreditation, p 107

23. Dupuy J, Gaudin R, D'Onofrio G (1990) Etude à l'aide d'urée enrichie en $15 \mathrm{~N}$ de la fertilisation azotée du riz inondé à Madagascar. 3. Cinétique de prélèvement de l'azote apporté sous forme de supergranules d'urée ou de perlurée au repiquage du riz inondé ou 21 jours après. L'Agron Trop 45:21-30

24. Wrobel MM, Bansagi T, Scott SK, Taylor AF, Bounds CO, Carranza A, Pojman JA (2012) pH wave-front propagation in the ureaurease reaction. Biophys $\mathrm{J}$ 103:610-615

25. Sigurdarson JJ, Svane S, Karring H (2018) The molecular processes of urea hydrolysis in relation to ammonia emissions from agriculture. Rev Environ Sci Bio/Technol 17:241-258

Publisher's Note Springer Nature remains neutral with regard to jurisdictional claims in published maps and institutional affiliations. 